\title{
Frequencies of Blood Group Systems MNS, Diego, and Duffy and Clinical Phases of Carrion's Disease in Amazonas, Peru
}

\author{
Oscar Acosta, ${ }^{1,2,3}$ Luis Solano, ${ }^{1}$ Jorge Escobar, ${ }^{4}$ Miguel Fernandez, \\ Carlos Solano, ${ }^{1}$ and Ricardo Fujita ${ }^{2}$ \\ ${ }^{1}$ Institute of Tropical Medicine Daniel A. Carrion, Faculty of Medicine, Major National University of San Marcos, Lima, Peru \\ ${ }^{2}$ Genetics and Molecular Biology Center, Faculty of Medicine, University of San Martin of Porres, Lima, Peru \\ ${ }^{3}$ Institute of Biological Chemistry, Microbiology and Biotechnology, Faculty of Pharmacy and Biochemistry, \\ Major National University of San Marcos, Lima, Peru \\ ${ }^{4}$ Peruvian Ministry of Health (MINSA), Direction of the Sub Region of Health Bagua, Bagua Grande, Amazonas, Peru \\ ${ }^{5}$ Peruvian Ministry of Health (MINSA), General Direction of Environmental Health (DIGESA), Lima, Peru \\ Correspondence should be addressed to Oscar Acosta; oacostac@yahoo.com
}

Received 31 August 2013; Revised 7 February 2014; Accepted 20 February 2014; Published 31 March 2014

Academic Editor: Jose G. Estrada-Franco

Copyright (C) 2014 Oscar Acosta et al. This is an open access article distributed under the Creative Commons Attribution License, which permits unrestricted use, distribution, and reproduction in any medium, provided the original work is properly cited.

\begin{abstract}
Carrion's disease (CD), is a human bartonellosis, that is, endemic in the Andes of Peru, Ecuador, and Colombia. Bartonella bacilliformis, a native hemotrophic bacteria, is the causative agent of $\mathrm{CD}$, and the interaction with the host could have produced changes in the gene frequencies of erythrocyte antigens. The goal here is to investigate the relationship between allele frequencies of blood group systems MNS, Diego, and Duffy and the clinical phases of CD, within a genetic context. In this associative and analytical study, 76 individuals from Bagua Grande, the province of Utcubamba, and the department of Amazonas in Peru, were enrolled. Forty of them resided in Tomocho-Collicate-Vista Hermosa area (high prevalence of cases in chronic phase, verrucous, or eruptive phase, without previous acute phase). Thirty-six individuals were from the area of Miraflores (high prevalence of cases in acute phase only) and were evaluated for blood group systems MNS, Diego, and Duffy. This study constitutes one of the first attempts at evaluating the genetic factors and clinical phases of CD. No significant statistical differences $(P>0.05)$ between allele frequencies of blood groups MNS, Diego, and Duffy and the prevalence of chronic and acute phases were detected in the two areas of Amazonas, Peru.
\end{abstract}

\section{Introduction}

Carrion's disease $(\mathrm{CD})$ is a human bartonellosis, an infectious pathology caused by Bartonella bacilliformis (B. bacilliformis), a bacteria native to the Andes, which is able to enter the bloodstream and parasitically invade erythrocytes (Figure 1). It is transmitted to humans through the bite of hematophagous insects of the genus Lutzomyia, mainly the species $L$. verrucarum $[1,2]$. At present, it is endemic in the Andes (between $500 \mathrm{~m}$ and 3200 meters above sea level) and the coastal and Amazonian and inter-Andean valleys of Peru, Ecuador, and Colombia. However, it has recently been found to be spreading and emerging in lower ecosystems in some coastal and Amazonian locations. In Peru, human bartonellosis has been found in different regions along the
Andes such as Piura, Amazonas, Cajamarca, La Libertad, Ancash, Lima, Huancavelica, Ayacucho, and Cusco $[3,4]$.

The Carrion disease has been divided in to several clinical phases; two of the most remarkable are as follows: (1) the hematic or acute phase, known as "Oroya fever," common symptoms of which are fever, hemolytic anemia, cephalea, pallor, myalgias, artharlgias, and loss of consciousness and (2) the eruptive or verrucous phase, termed "verruga peruana" (Peruvian wart), which appears after the recovery from the acute phase, reddish verrucous eruptive lesions of different sizes and shapes characterize this phase, in some cases, patients without a history of the acute illness can display this phase $[4,5]$.

In endemic areas, the presence of asymptomatic carriers is important; research so far has indicated humans to be 


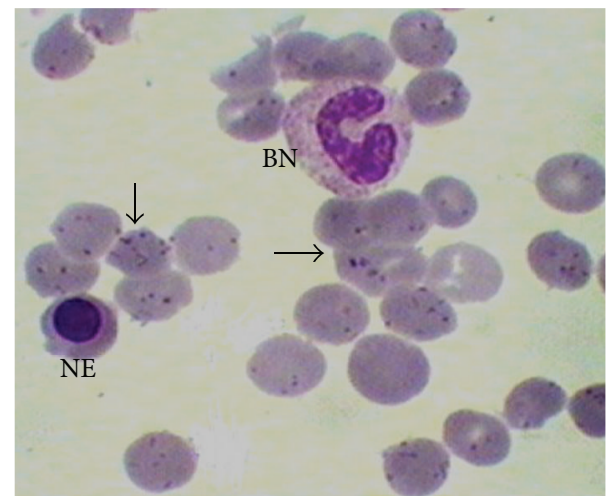

FIgURE 1: Blood smear of patient in acute phase. Parasitized erythrocytes by bacillary and coccoid forms of B. bacilliformis (arrows), a nucleated erythrocyte (NE), and a band neutrophil (BN) can be observed. Giemsa stain, 1000x.

the only reservoir of the bacterium. Evidence suggests that outbreaks of bartonellosis represent the emergence, in areas of nonendemicity, or the resurgence of the disease, which appears to be an infectious emerging or reemerging pathology with a wide geographic range $[4,6]$.

Several studies $[1,5,7]$ have been conducted with the clinical aspects, traditional epidemiology, geographical distribution, and molecular biology of the bacterium and other topics related to $B$. bacilliformis. Epidemiological data shows that in some closely situated Peruvian areas, differences in the predominance of the $\mathrm{CD}$ phases can be noted. Comparison of the clinical phases in localities within the district of Bagua Grande, Amazonas department, showed different distributions of either the verrucous or hematic phases. In TomochoCollicate-Vista Hermosa there was a prevalence of verrucous cases (81 affected individuals versus 5 hematic occurrences), whereas, in the nearby location of Miraflores, there were 12 hematic cases and only 5 verrucous affected individuals. This information was obtained by MF and JE (data not published) and Records of the Epidemiological Week N ${ }^{\circ} 32$, August 2004 (provided by Epidemiological Office, Subregion of BaguaAmazonas, Ministry of Health).

The local population is apparently mestizo (mostly Andean and Caucasian genetic background), most of whom are migrants coming from the Andean department of Cajamarca (communication of Subregion of Bagua-Amazonas).

Genetic factors can exert a great influence on the susceptibility, resistance, and/or tolerance to infectious disease, not only at an individual but also at a population level. It is well known that some genetic traits considered of risk are present in modern human populations and that they arise independently due to selective pressure of infections. Thus, mutant globins, glucose-6-phosphate dehydrogenase (G6PD), and Duffy antigen genes are paradigmatic examples of malaria protection. An abnormally high prevalence of deleterious mutant alleles is present in populations of the Tropical Belt areas around the world. For example, the enzyme G6PD is involved in malaria protection but its homozygous state predisposes to hemolytic anemia. People with an absent Duffy antigen are also protected against malaria by Plasmodium vivax ( $P$. vivax) because the pathogen uses it to invade erythrocytes [8-11].

Very little information is available from South American populations about this aspect. There are native parasites that cause endemic diseases since pre-Columbian times such as Trypanosoma cruzi, Leishmania peruviana, and B. bacilliformis $[12,13]$ and it is possible that they have influenced the distribution of different alleles by selective pressure. Although the malaria is important, the pre-Columbian presence of $P$. vivax has been subject to great debate and remains unclear [14].

We postulate that Amerindian hosts have possibly developed mechanisms of susceptibility, resistance, or tolerance with regard to genetic composition which may be associated with the clinical phases of CD. One strategy to test this hypothesis is to search for genes or molecular markers in which selective pressure can be exerted by $B$. bacilliformis and to evaluate the variation of allele frequencies of the genes in human populations.

Specifically, this can be verified by variation of erythrocyte antigens (receptor molecules for the bacterium) and cellular and humoral immunity. According to Buckles and McGinnis [15], glycophorins A/B and band 3 act as receptors for $B$. bacilliformis adhesion and invasion molecules such as flagellin, adhesin, deformin, IaIA, and IaIB. Glycophorins $\mathrm{A} / \mathrm{B}$ and band 3 are closely related with blood group systems MNS and Diego [16]. On the other hand, Duffy group is associated with resistance to malaria by $P$. vivax in populations living in endemic areas in Africa and Oceania $[17,18]$. It is possible that, in Bartonella infection, Duffy glycoproteins are involved as receptor molecules. Thus, variability or polymorphisms of blood group systems could be related with susceptibility, resistance, and/or tolerance to infection, as well as with the prevalence of the disease's clinical phases.

In this study, genetic and coevolutionary principles are applied in order to investigate the relationship between the genetics of Amerindian host and clinical phases of $\mathrm{CD}$, an infectious pathology that can be found in most of the Andean departments of Peru.

Specifically, the goal is to investigate the relationship between clinical phases of $\mathrm{CD}$ and the allele frequencies of blood group systems MN, Ss, Diego, and Duffy under a genetic coevolutionary context, that is, under selective pressure of $B$. bacilliformis over the Amerindian host. This research is one of the first attempts to evaluate genetic factors and clinical phases of this ancient disease from the Andes. For this purpose, we have taken advantage of the differences between Tomocho-Collicate-Vista Hermosa (predominance of verrucous phase) and Miraflores (predominance of hematic disease). We will compare the allele frequencies of the blood group systems MN, Ss, Diego, and Duffy between these two areas.

\section{Materials and Methods}

2.1. Areas of Study and Participants. CD is endemic within the area of study corresponding to the district of Bagua 
Grande $\left(05^{\circ} 46^{\prime} 40^{\prime \prime}\right.$ South, $78^{\circ} 25^{\prime} 46^{\prime \prime}$ West), province of Utcubamba, department of Amazonas, in the Northern Upper Amazonian Jungle of Peru at 540 meters above sea level (Figure 2). We have analyzed samples at two locations with different prevalence of either the verrucose or hematic forms according to the Annual Report and Epidemiologic Bulletin Subregion of Health Bagua-Amazonas, Peru, 2004. General and clinical data was collected for each of the 40 individuals from Tomocho-Collicate-Vista Hermosa localities (prevalence verrucose form or chronic phase) and for the 36 from Miraflores district (prevalence hematic form or acute phase), using convenience sampling.

2.2. Biological Sample. The sampling was performed in September 2004 (Epidemiological Week no 36). Each of the 76 individuals signed a written consent form before samples were collected. Five to $10 \mathrm{~mL}$ of peripheral blood were collected in Vacutainer sterile tubes (Becton Dickinson, Franklin Lakes, NJ) containing anticoagulant EDTA or sodium citrate. The samples were kept under refrigeration until they were processed for blood groups at the Laboratory for Bartonellosis, Daniel A. Carrion Tropical Medicine Institute, Universidad Nacional Mayor de San Marcos (UNMSM). This study was presented to and approved by the Scientific and Ethic Committee Faculty of Medicine, UNMSM. In addition, the project was approved and authorized by the Subregional Director of Health in Amazonas and Bagua's Hospital.

2.3. Determination of Blood Groups. Blood typing was performed according to antisera manufacturer's specifications (Immucor Gamma Biological, USA): group MN was determined by monoclonal anti-M and anti-N antisera through a direct method in test tubes. While blood groups Ss, Diego, and Duffy were determined by polyclonal anti-S, anti-s, anti-Dia, anti-Fya, and anti-Fyb antisera through Human Antiglobulin test and test tube method.

2.4. Statistical Analysis. Allele frequencies, based on phenotype frequencies, were obtained by a direct counting method. In order to evaluate the frequencies, a Chi-square test $\left(\chi^{2}\right)$ was used to estimate the Hardy-Weinberg equilibrium. A $\chi^{2}$ or Fisher's exact test was applied to establish allelic association of blood groups and clinical phases according to the area. SPSS 15.0 statistical software and population genetics software were used for calculations.

\section{Results}

As may be seen in Table 1, we sampled 40 individuals in Tomocho-Collicate-Vista Hermosa (prevalence of chronic form), 17 of which (42.5\%) were males and 23 were females $(57.5 \%)$. The average age was 23.5 with a standard deviation of \pm 10.6 . The prevalent clinical phase was the chronic form in 22 cases (57.5\%), with only one case of the acute phase (2.5\%). CD was not found in 17 (42.5\%) of individuals.

The Miraflores group (prevalence of acute form) consisted of 36 individuals, 14 males (38.9\%) and 22 females

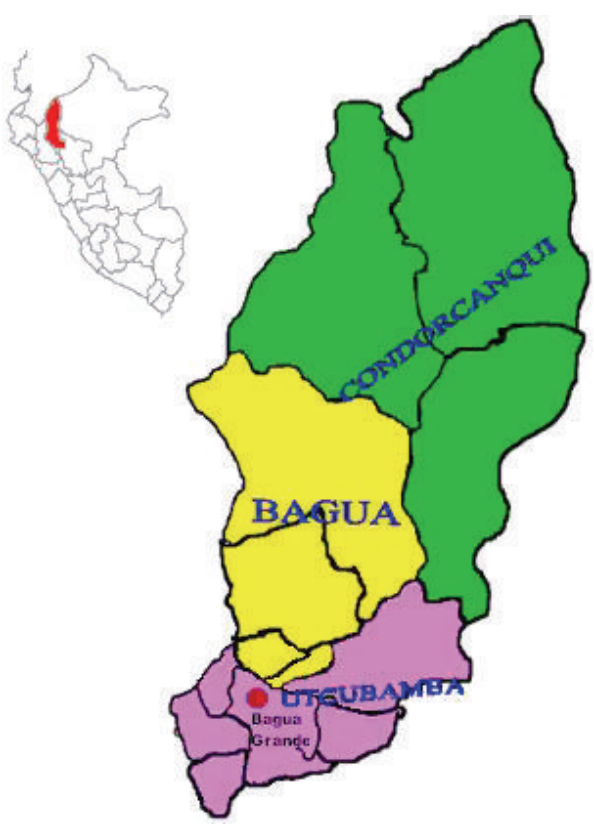

FIgURE 2: Location of the sampled areas in Bagua Grande (red spot), province of Utcubamba, department of Amazonas, Peru. At left top, map of Peru with location of department (filled in red).

(61.1\%). The average age was 29 with a standard deviation of \pm 22.9 . Of these 36 individuals, 12 presented with only acute phase $(33.3 \%), 23$ were healthy $(63.8 \%)$, and one case displayed the chronic and acute phases simultaneously $(2.7 \%)$.

The biased and compartmentalized distribution of distinct clinical phases in two different but geographically proximal areas, Tomocho-Collicate-Vista Hermosa (prevalence of verrucous phase) and Miraflores (prevalence of hematic phase), promoted us to compare the distribution of phenotype frequencies of the MN, Ss, Diego, and Duffy blood group systems in both areas.

We performed the analysis of the phenotype frequencies of the MN, Ss, Diego, and Duffy blood group systems and found that they were in Hardy-Weinberg equilibrium (Table 2). Thus, at this moment we do not have any evidence of selective pressure on these blood systems. The frequencies of blood group systems were similar in both areas and the $\mathrm{MN}$ blood group system was the most variable.

For the MN blood system an increase in the frequency of heterozygotes in Tomocho-Collicate-Vista Hermosa ( $\mathrm{MM}=$ $0.375, \mathrm{MN}=0.575$ ) was found in comparison to Miraflores $(\mathrm{MM}=0.5 ; \mathrm{MN}=0.389)$, but it was not statistically significant. However, when the alleles were compared, a much narrower distribution was found, in Tomocho-Collicate-Vista Hermosa the $\mathrm{M}=0.6625$ and $\mathrm{N}=0.3375$ versus $\mathrm{M}=$ 0.6945 and $\mathrm{N}=0.3055$ in Miraflores. In both comparisons of distributions of phenotypes and allele frequencies of $\mathrm{MN}$ blood group, no significant statistical differences were found between the two areas (Table 2).

In the comparisons of blood group systems Ss, Diego, and Duffy, no evident differences were seen either in phenotypes 
TABLE 1: General data and clinical phases of the samples analyzed in this study.

\begin{tabular}{|c|c|c|}
\hline Characteristics & $\begin{array}{l}\text { Tomocho-Collicate-Vista Hermosa } \\
n(\%)\end{array}$ & $\begin{array}{c}\text { Miraflores } \\
n(\%)\end{array}$ \\
\hline Sample & 40 & 36 \\
\hline \multicolumn{3}{|l|}{ Sex } \\
\hline Male & $17(42.5)$ & $14(38.9)$ \\
\hline Female & $23(57.5)$ & $22(61.1)$ \\
\hline Total & $40(100.0)$ & $36(100.0)$ \\
\hline \multicolumn{3}{|l|}{ Age } \\
\hline$X \pm \mathrm{SD}$ years & $23.5 \pm 10.6$ & $29.5 \pm 22.9$ \\
\hline \multicolumn{3}{|l|}{ Clinical phases* } \\
\hline Acute phase only & $1^{\mathrm{a}}$ & 12 \\
\hline Chronic phase only & 22 & 0 \\
\hline Acute and chronic phases & 0 & $1^{\mathrm{b}}$ \\
\hline No reported disease or healthy & 17 & 23 \\
\hline Total & 40 & 36 \\
\hline Total for analysis & $39^{\mathrm{a}}$ & $35^{\mathrm{b}}$ \\
\hline
\end{tabular}

$X \pm \mathrm{SD}$ is the median \pm standard deviation.

${ }^{*}$ Clinical phases' data of each individual were obtained by self-report (personal interviews) and/or review of clinical records for verification of treatment or supervision of the Carrion's disease.

${ }^{a}$ One individual had acute phase and was removed from the analysis "blood group versus clinical phase" in Tomocho-Collicate-Vista Hermosa area, reducing our sample from 40 to 39 individuals.

${ }^{\mathrm{b}}$ One individual had acute and chronic phases and was removed from the analysis "blood group versus clinical phase" in Miraflores area, reducing our sample from 36 to 35 individuals.

or alleles. There was, therefore, an absence of statistical differences in all blood group systems with regard to phenotypes and allele frequencies in the two areas (Table 2).

To test the hypothesis that the clinical phases of $\mathrm{CD}$ are associated with blood groups, we seek the possible association between phenotypes and alleles of MN, Ss, Diego, and Duffy with the benign (chronic or verrucose) and nonbenign (acute or hematic) clinical phases. Forty individuals were from Tomocho-Collicate-Vista Hermosa districts (prevalence of the verrucose phase) and 36 from Miraflores district (prevalence of the hematic phase). It may be seen, however, that in each group there was one atypical individual for the prevalence of the respective location (one acute case in Tomocho-Collicate-Vista Hermosa and one chronic case in Miraflores). These individuals were removed for subsequent analysis. Therefore, we have selected 39 individuals from Tomocho-Collicate-Vista Hermosa: 22 cases of chronic phase and 17 with no bartonellosis registered and from Miraflores we have 35 individuals: 12 cases of acute phase and 23 with no bartonellosis (Table 3).

The differences of phenotype or alleles among cases versus occurrences of no bartonellosis in each area are nonsignificant statistical. We have also compared the clinical phases and phenotypes or alleles frequencies between areas, and again no significant statistical differences were found (Table 3).

\section{Discussion and Conclusion}

Carrion's disease, a human bartonellosis, is characterized by two well defined clinical phases. One phase is the hematic, anemic, febrile, or acute phase that is devastating and may be fatal and the other is the chronic, eruptive, verrucous phase that is a benign phase [3].

The present and previous work have shown that there is an evident difference of the distribution of the acute and the chronic CD phases in the district of Bagua Grande (MF and JE, not published results, and Annual Report and Epidemiologic Bulletin Subregion of Health Bagua-Amazonas, Peru, 2004). The reason why Tomocho-Collicate-Vista Hermosa displays high prevalence of the chronic phase and Miraflores predominantly displays the acute phase remains without explanation at present. A differential genetic response of the host could be invoked but at this time there is no historical or cultural information concerning the ethnic backgrounds of Miraflores versus Tomocho-Collicate-Villa Hermosa residents. Under the same logic, distinct genotypes-phenotypes linked to a differential distribution of $B$. bacilliformis strains or Lutzomyia spp. vector may also be hypothesized, but as yet no proof has been found. Molecular genetic characterization of the pathogen and vector species in bartonellosis needs to be taken into account for future studies concerning the differential distribution in the district of Bagua Grande.

A study regarding the mechanisms of $B$. bacilliformis invasion has revealed the participation of erythrocyte antigens (glycophorins A/B and band 3). Since these molecules are closely related to blood group systems $\mathrm{MN}$, Ss, Diego [15], and Duffy group, it is possible that they could be involved as receptor molecules. All of these proteins are present in the erythrocyte membranes and are involved in the entrance of pathogens like Plasmodium. Homozygous defective mutations for these proteins have been reported 


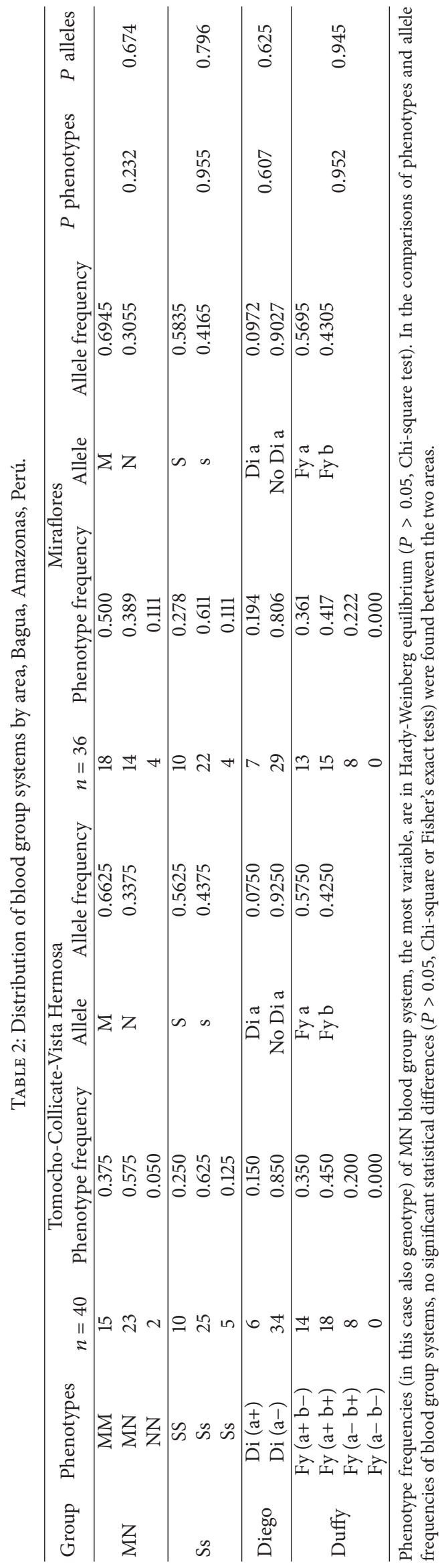




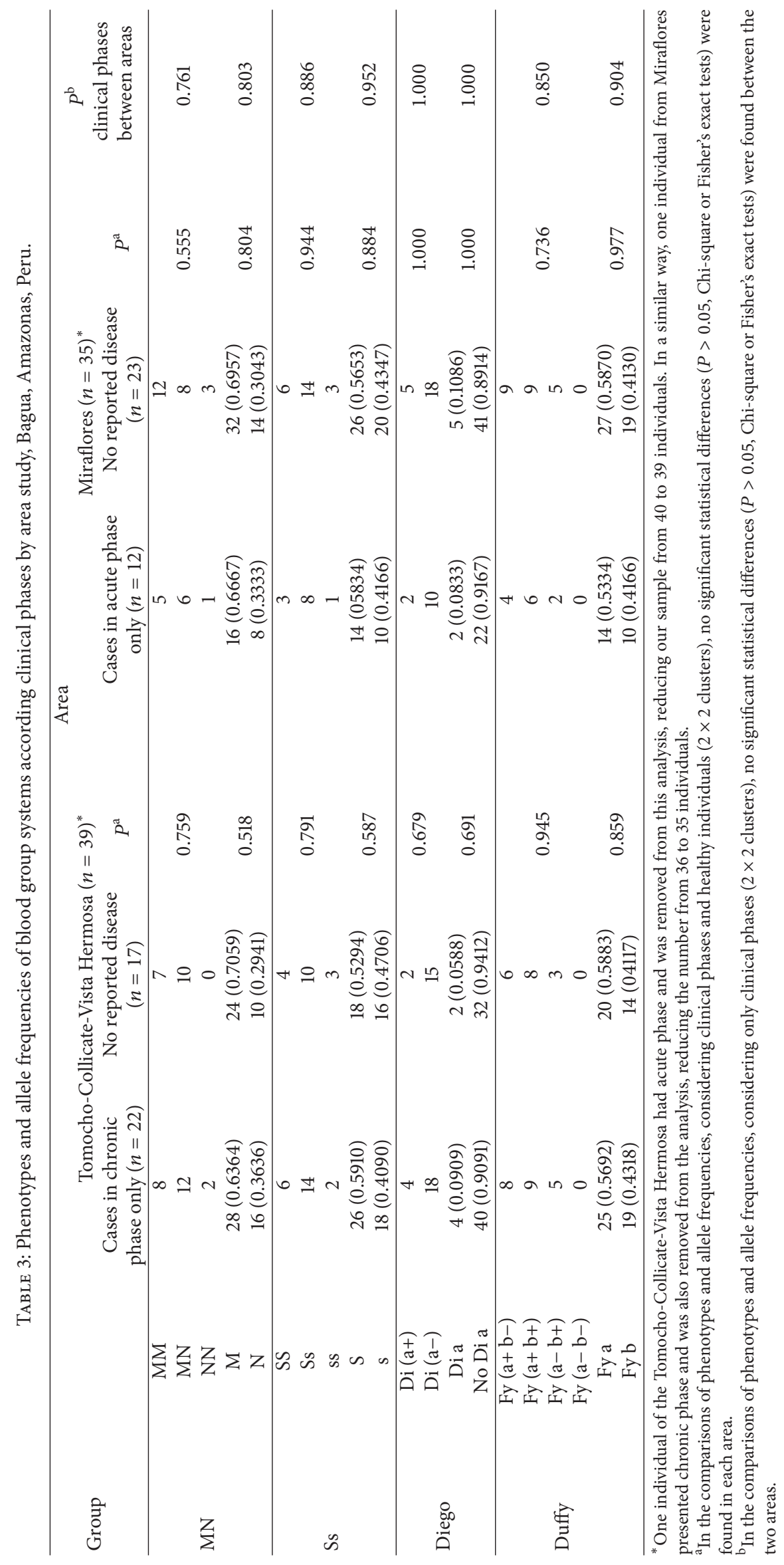


as being protective for malarial infection in Africa and Asia [19]. Very little information is available from South American populations but some studies in Brazil and Colombia have confirmed that Duffy, $\mathrm{MN}$, and Ss variant blood groups are resistant to $P$. falciparum infection in some populations [2022 ], although this concerns the protozoan, studies in bacteria such as B. bacilliformis are currently underway.

In our hypothesis, we postulated that selective pressure exerted by this bacterium could have determined different phenotype frequencies of the blood groups from each area under study. Our results indicate no relationship between blood groups and locations that have biased prevalence either with the chronic phase (Tomocho-Collicate-Vista Hermosa) or the acute phase (Miraflores). Phenotypes and allele of blood group systems MN, Ss, Diego, and Duffy do not show a statistically significant $(P>0.05)$ difference between the frequencies found in Tomocho-CollicateVista Hermosa compared with the frequencies in Miraflores (Table 2).

Although there was no significant difference $(P>0.05)$ in the MN blood group, which is in Hardy-Weinberg equilibrium in both areas, the incidence of heterozygosity was higher in Tomocho-Collicate-Vista Hermosa than in Miraflores. It is therefore tempting to speculate a heterozygote advantage in Tomocho-Collicate-Vista Hermosa favoring the chronic state. It should however be noted that the nonstatistically relevant differences outlined above could result from the small sample size of this investigation.

The general tendency of no association found with $\mathrm{MN}$ and clinical phase continues when we compare Ss, Diego, and Duffy blood group systems alleles with nonaffected individuals and cases of chronic and acute phases (Table 3 ). However, these data must be considered as preliminary in order to make general inferences about the infection associated with blood group systems or erythrocyte antigens. Other gene variants associated with infectious processes such as genes for toll-like receptors, interleukins, lectins, HLA, cytokines, and other proteins of the innate and acquired immunoinflammatory responses, including microRNA polymorphisms, expression, exomes, and ancestry informative markers (AIMs) need to be tested. Moreover, molecular genetic analysis of bacterium and genetic variability of insect vectors should also be considered $[8,23,24]$.

On one hand, the results of this study cannot be extrapolated to other regions of Peru where the disease is also found, since there are differences in the genetic composition of Peruvian subpopulations. The prevalence of the clinical phase and history of outbreaks and reappearances [7] will be very important information when exploring genetic studies amongst these subpopulations. On the other hand, this study has contributed to the knowledge concerning the genetic variability of subpopulations of Bagua Grande, Amazonas.

In conclusion, our results showed no significant statistical differences between allele frequencies of blood groups MNS, Diego, and Duffy and the prevalence of clinical phases of the Carrion's disease in the district of Bagua Grande, department of Amazonas, Peru.

\section{Conflict of Interests}

The authors declare that there is no conflict of interests regarding the publication of this paper.

\section{Acknowledgments}

The authors thank the people and authorities from TomochoCollicate-Vista Hermosa and Miraflores in Bagua Grande, Amazonas, for their support in this study. In addition, they wish to express their sincere gratitude to health personnel from both areas, including Dr. Isaac Palma and Dr. Andres Córdoba for their valuable collaboration. They also thank Matt Bawn, Ph.D., for a detailed review of English. For their financial support, they wish to also thank the Faculty of Medicine, Universidad Nacional Mayor de San Marcos (Proyecto FEDU), and the Faculty of Human Medicine, Universidad de San Martín de Porres (Proyecto Inmunogenética-E10012014022).

\section{References}

[1] G. C. Gray, A. A. Johnson, S. A. Thornton et al., "An epidemic of Oroya fever in the Peruvian Andes," American Journal of Tropical Medicine and Hygiene, vol. 42, no. 3, pp. 215-221, 1990.

[2] L. Solano and V. Solano, "La Enfermedad de Carrión y la Biología de Bartonella bacilliformis," Revista Peruana de Medicina Tropical UNMSM, vol. 5, pp. 13-18, 1991.

[3] C. Maguiña, Bartonelosis o Enfermedad de Carrión: Nuevos aspectos de una vieja enfermedad, Editor Importadores, Lima, Peru, 1998.

[4] OGE/INS, Epidemiología de la Bartonelosis en el Perú, Serie Documentos Monográficos, Módulos Técnicos, Lima, Peru, 2000.

[5] M. Kosek, R. Lavarello, R. Gilman et al., "Natural History of Infection with Bartonella bacilliformis in a Nonendemic Population," The Journal of Infectious Diseases, vol. 3, pp. 865$872,2000$.

[6] L. Solano, L. Marocho, A. Caceres et al., "Estudio de reservorios de Bartonella bacilliformis," Revista Peruana de Medicina Tropical UNMSM, vol. 1, pp. 71-74, 2004.

[7] G. Greub and D. Raoult, "Bartonella: new explanations for old diseases," Journal of Medical Microbiology, vol. 51, no. 11, pp. 915923, 2002.

[8] G. Aguileta, G. Refrégier, R. Yockteng, E. Fournier, and T. Giraud, "Rapidly evolving genes in pathogens: methods for detecting positive selection and examples among fungi, bacteria, viruses and protists," Infection, Genetics and Evolution, vol. 9, no. 4, pp. 656-670, 2009.

[9] G. S. Cooke and A. V. S. Hill, "Genetics of susceptibility to human infectious disease," Nature Reviews Genetics, vol. 2, no. 12, pp. 967-977, 2001.

[10] R. Medzhitov, "Damage control in host-pathogen interactions," Proceedings of the National Academy of Sciences of the United States of America, vol. 106, no. 37, pp. 15525-15526, 2009.

[11] D. J. Weatherall, J. I. Bell, J. B. Clegg et al., "Genetic factors as determinants of infectious disease transmission in human communities," Philosophical Transactions of the Royal Society of London B: Biological sciences, vol. 321, no. 1207, pp. 327-348, 1988. 
[12] M. J. Allison, A. Pezzia, E. Gerszten, and D. Mendoza, "A case of Carrion's disease associated with human sacrifice from the Huari culture of Southern Perú," American Journal of Physical Anthropology, vol. 41, no. 2, pp. 295-300, 1974.

[13] J. Verano and G. Lombardi, "Paleopatología en Sudamérica andina," Bulletin de l'Institut Français d'Etudes Andines, vol. 1, pp. 91-121, 1999.

[14] L. A. Cormier, "The historical ecology of human and wild primate malarias in the new world," Diversity, vol. 2, no. 2, pp. 256-280, 2010.

[15] E. L. Buckles and E. McGinnis, "Interaction of Bartonella bacilliformis with human erythrocyte membrane proteins," Microbial Pathogenesis, vol. 29, no. 3, pp. 165-174, 2000.

[16] "SCARF (Serum, Cells and Rare Fluid Exchange)," http:// scarfex.jove.prohosting.com/exchange.history.html.

[17] A. G. Maier, M. T. Duraisingh, J. C. Reeder et al., "Plasmodium falciparum erythrocyte invasion through glycophorin $\mathrm{C}$ and selection for Gerbich negativity in human populations," Nature Medicine, vol. 9, no. 1, pp. 87-92, 2002.

[18] L. H. Miller, S. J. Mason, D. F. Clyde, and M. H. McGinniss, "The resistance factor to Plasmodium vivax in blacks. The Duffy blood group genotype, FyFy," The New England Journal of Medicine, vol. 295, no. 6, pp. 302-304, 1976.

[19] D. P. Blackall, J. K. Armstrong, H. J. Meiselman, and T. C. Fisher, "Polyethylene glycol-coated red blood cells fail to bind glycophorin $\mathrm{A}-$ specific antibodies and are impervious to invasion by the Plasmodium falciparum malaria parasite," Blood, vol. 97, no. 2, pp. 551-556, 2001.

[20] B. Beiguelman, F. P. Alves, M. M. Moura et al., "The association of genetic markers and malaria infection in the Brazilian western Amazonian region," Memorias do Instituto Oswaldo Cruz, vol. 98, no. 4, pp. 455-460, 2003.

[21] C. E. Cavasini, L. C. de Mattos, R. T. Alves et al., "Frequencies of ABO, MNSs, and Duffy phenotypes among blood donors and malaria patients from four Brazilian Amazon areas," Human Biology, vol. 78, no. 2, pp. 215-219, 2006.

[22] F. Montoya, M. Restrepo, A. E. Montoya, and W. Rojas, "Blood groups and malaria," Revista do Instituto de Medicina Tropical de Sao Paulo, vol. 36, no. 1, pp. 33-38, 1994.

[23] L. Abel and A. J. Dessein, "The impact of host genetics on susceptibility to human infectious diseases," Current Opinion in Immunology, vol. 9, no. 4, pp. 509-516, 1997.

[24] A. V. S. Hill, "The genomics and genetics of human infectious disease susceptibility," Annual Review of Genomics and Human Genetics, vol. 2, pp. 373-400, 2001. 


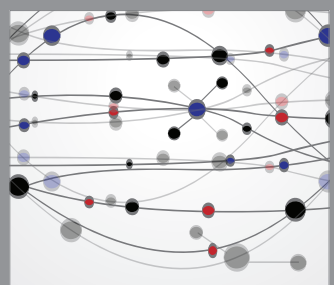

The Scientific World Journal
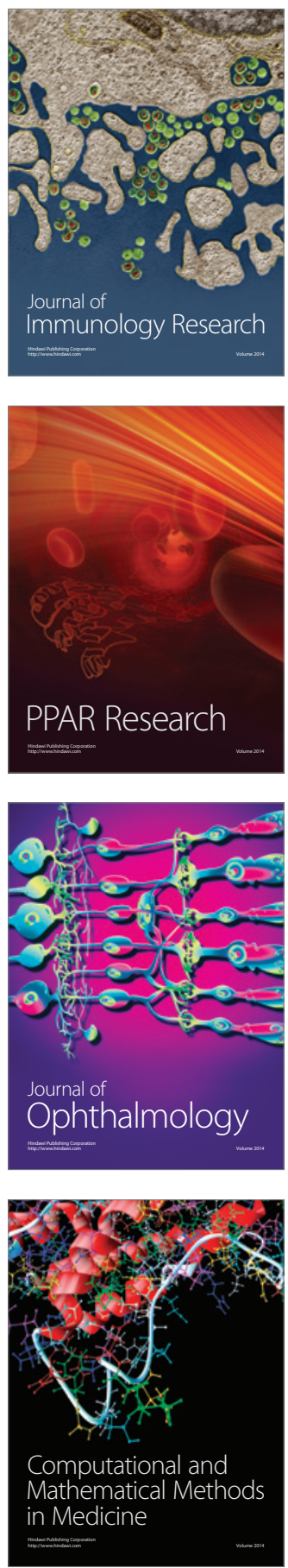

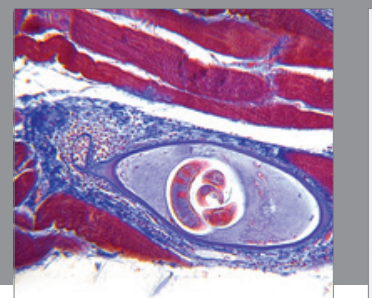

Gastroenterology

Research and Practice
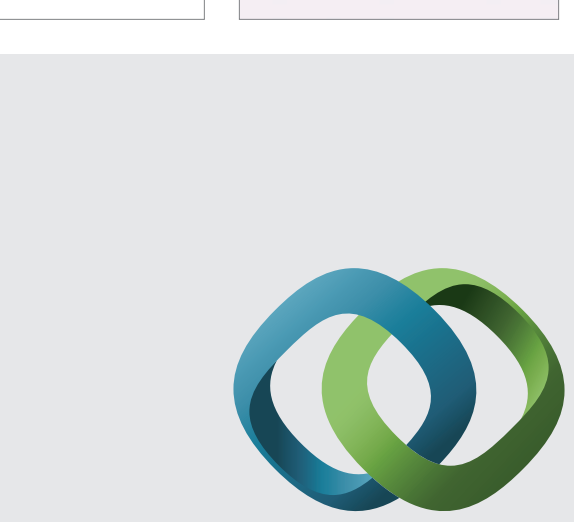

\section{Hindawi}

Submit your manuscripts at

http://www.hindawi.com
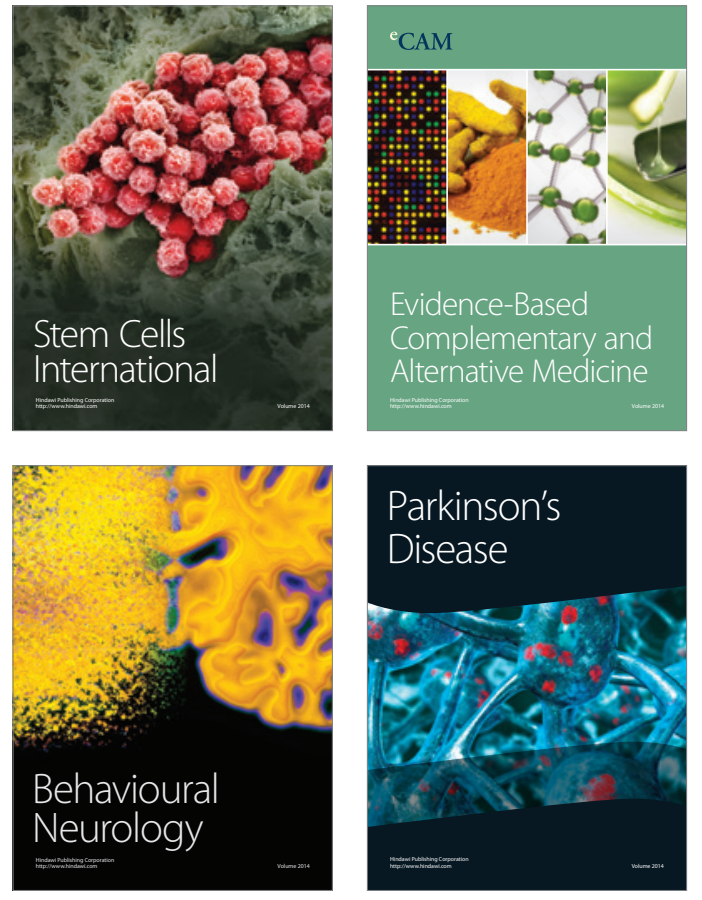
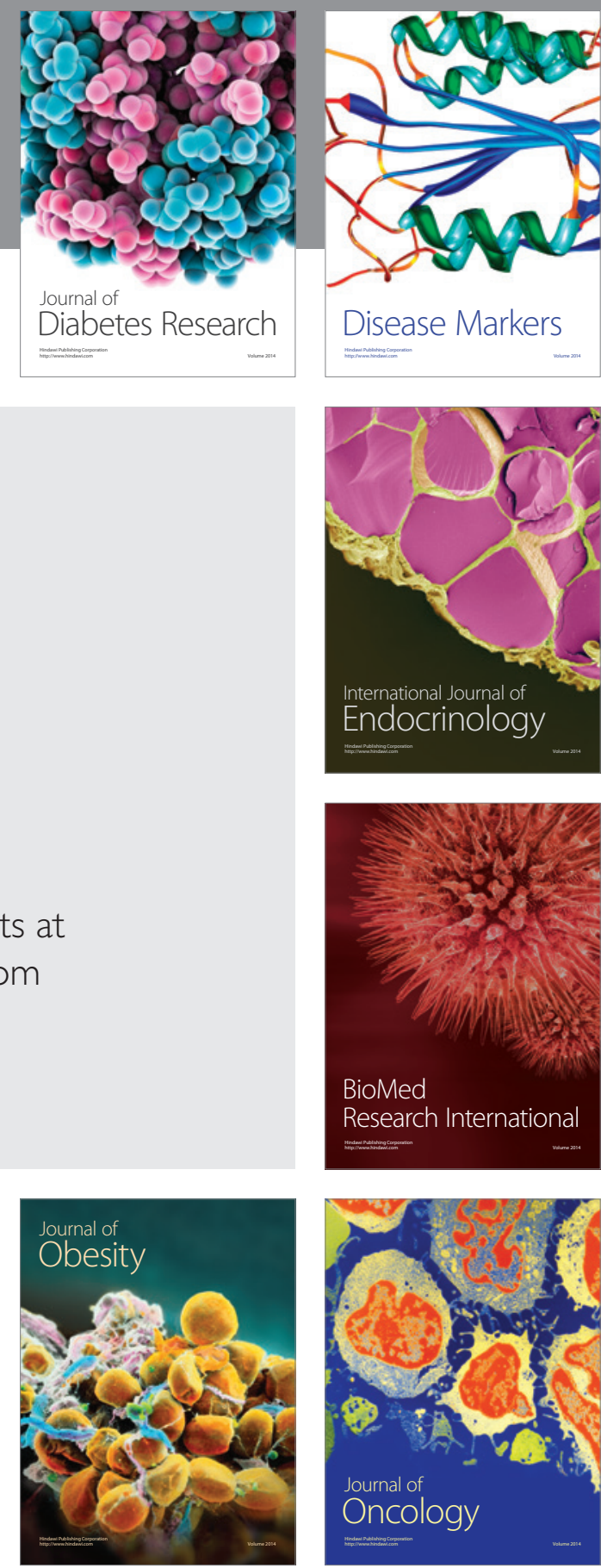

Disease Markers
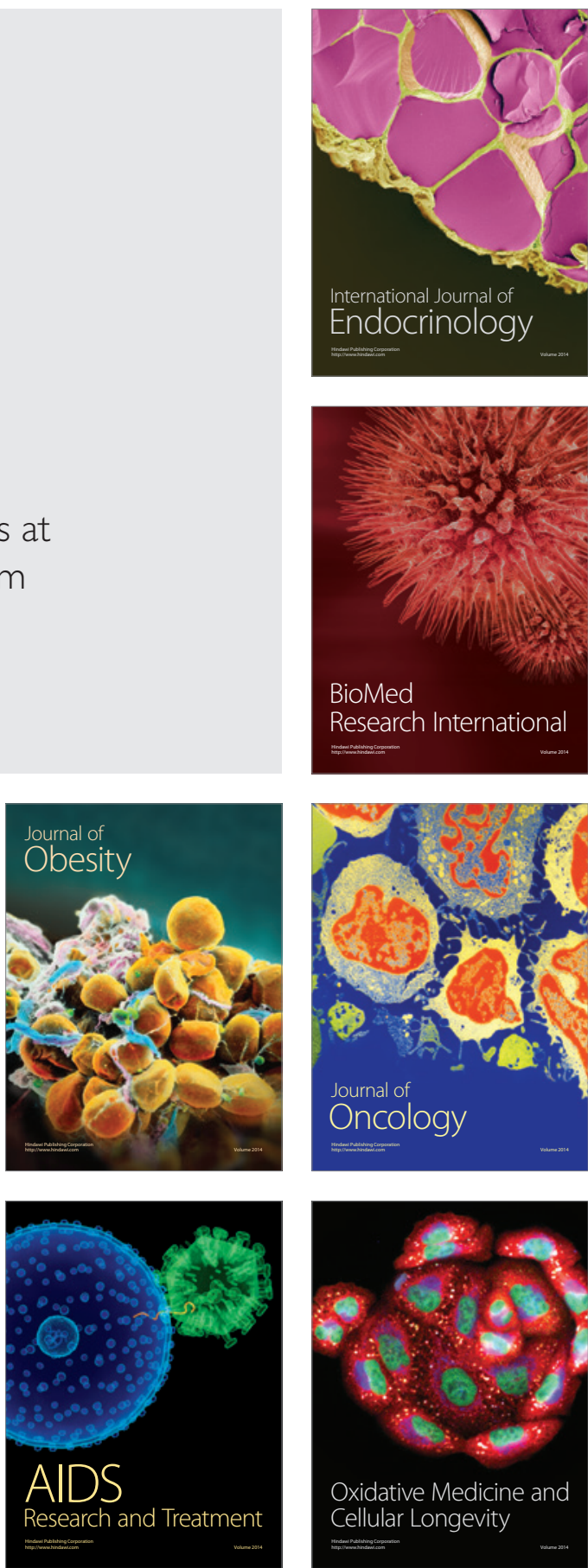